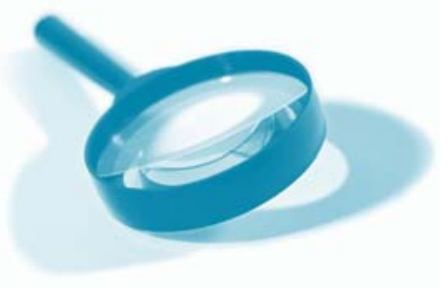

\title{
Preliminary investigations into the selective use of concept maps in tea ching introductory physic al chemistry to non-chemistry specialist students
}

\author{
Julia Percival \\ Department of Chemistry \\ University of Surrey \\ Guildford \\ Surrey GU2 7XH \\ j.percival@surrey.ac.uk
}

\section{Simon Lygo-Baker \\ Centre for Education and \\ Academic Development \\ University of Surrey \\ Guildford \\ Surrey GU2 7XH}

Physical chemistry topics are historically considered complex

to teach and challenging to learn for many lecturers and students. The combination of relatively abstract ideas with a considerable mathematical component challenges most students and can be too much for some.

\begin{abstract}
Recently we have undertaken a preliminary study on the introduction of concept mapping into a physical chemistry module being delivered to non-chemistry specialist students. Previously this module was known for being conceptually challenging and more unpopular amongst biological sciences students than other biological modules of similar difficulty. Here, we discuss the introduction of concept maps at certain points in the module to assist with student's ability to connect ideas and therefore answer questions they have not previously been able answer reliably. These are combined with additional large group workshops and in-lecture examples to help the students to connect the questions with the course content. Also included are the experiences of the staff delivering the module before and after this introduction and some qualitative feedback from the students involved. This study has since lead to a change in the way introductory physical chemistry is taught to non-chemistry students at Surrey and has informed teaching methods for subsequent years.

\section{Introduction}

Physical chemistry topics are historically considered complex to teach and challenging to learn for many lecturers and students ${ }^{1}$. The combination of relatively abstract ideas with a considerable mathematical component challenges most students and can be too much for some. Overcoming challenges in the teaching of this subject is an ongoing and fluid process. Academic staff are challenged to find ways of supporting learning and methods used to enable this have been found to vary significantly ${ }^{2}$. However, summative assessment remains fairly standard and the major source of feedback for students in many institutions. As such this may motivate students to focus on obtaining good marks in their work and to do so by selecting the easiest route, negating efforts made by those teaching them ${ }^{3}$. Academic structures may further encourage surface approaches as the nature of summative assessment, especially in unseen exam format, can suggest that the easiest way for the students to gain their marks is not always the way the students will best understand the material presented.
\end{abstract}

It has been documented previously that surface learning ${ }^{4}$ is often employed by students in physical science and engineering subjects to get them through their exams. Traditionally students are required to answer questions on the course content and in order to do so, they rote learn the methods and mechanisms without fully grasping the topic, using practices they are familiar with from previous modes of learning. This lack of deep learning results in limited ability to utilise the knowledge they learn in more sophisticated ways as they start to be required to apply and analyse across the subjects studied.

The course discussed here is a physical and bioinorganic chemistry module for level 1 biochemistry students studying in the Faculty of Health and Medical Sciences at the University of Surrey. The module, BMS1001, is taught in the spring semester and follows an introductory general chemistry module in the first semester. Students taking biochemistry degree programs are required to have chemistry at A-level and to sit both chemistry modules as part of their first year. The students must obtain a pass in these modules in order to progress to the second year. 
BMS1001 is known locally as a relatively unpopular module. It contains some of the most complex chemistry the students will be taught during their degree and feedback suggests it is perceived as unrelated to other modules studied, which are predominantly biological topics. In addition, the module is taught by unfamiliar faces and has a relatively high level of mathematics. The combination of the abstract subject matter, unfamiliar lecturers and the level of mathematics appears to create a learning environment in which students appear unwilling or unable to grasp the relevance of the topics to their studies and as a result, attendance and marks are both known to be low. There is a distinct impression that students feel they will never need to use what is being taught other than to obtain passing marks in the assessment, which may encourage a surface learning approach which results in a rapid loss of knowledge once the assessment has been completed.

The aforementioned issues result in a challenging module to teach. The content includes bioinorganic chemistry, electrochemistry, kinetics, thermodynamics and solution chemistry topics. Of these topics, kinetics, thermodynamics and solution chemistry were involved in the project as these are taught by the same lecturer. The remaining topics were unchanged. The project goal was therefore to explore a new way to present the information contained within aspects of the module so as to keep students engaged and to examine whether it would help them to access deeper learning. To achieve this, a number of changes were made to the teaching of the relevant topics. Traditionally (and during the academic year 2009-10) the lectures were presented on PowerPoint slides with no formal workshops. Other than a summary slide at the end of a topic, there was no consolidation of the material presented and little structured opportunity for the students to practice what they had learnt. During the academic year 201011 changes were implemented and the results are presented here.

\section{Teaching Method Changes to BMS1001: Introducing a chemistry quiz at the beginning of the module}

Previously, there had been no attempt made to determine how much chemistry a student knew and so prior knowledge had always been assumed. These assumptions included that they understood common chemical symbols and nomenclature and that they knew how to perform basic chemistry calculations. Anecdotal evidence suggested that significant gaps existed. This was perceived to be a potential barrier to learning given that the high chemical content of the module required these fundamental skills to enable the students to access the material presented to them.

It was not possible to assess every student's prior knowledge individually and identify gaps and then resolve these in the given time. In an attempt to resolve this conundrum a quiz was devised which was given to the students at the start of the first lecture. The questions included basic mole and concentration calculations, identification of common symbols and basic mathematical operations.
Once the students had been given a period of time to work through the quiz, the author took the class through the answers, working through each question and explaining the reasoning. The students were instructed to write down what they had got wrong on their quiz and then to use it as a reference if they came across something they were unfamiliar with. The quiz was devised as a method for providing formative feedback and the answers were not collected from the students but could serve as a reminder as the learning module progressed.

While this did not guarantee the students would understand everything they were presented with, it did show up some common weaknesses that had also been noted elsewhere, such as understanding of basic concentration calculations and the ability to rearrange equations. This meant that the lecture content could be tailored more appropriately to the students needs.

An unintended benefit of this introductory quiz was that it appeared to put the students into a chemistry frame of mind from the start. It also laid out what they should already be able to do, prompting some students to seek help for things they were unsure about outside the class where they may not have done previously. In this way, each student had the opportunity to identify potential gaps in her/his knowledge and also highlighted to the lecturer common areas of misunderstanding.

\section{Use of concept maps as consolidation tools}

Previously, the content of the course was delivered in a didactic format, using presented slides. The content was talked through by the lecturer and the students took notes usually directly onto a handout. During this time, example calculations were presented and students were asked to do them during the lecture. These would then be worked through on additional slides which the students did not have copies of. Although this did potentially offer more active engagement, there was in reality little dialogue established either between students or with the lecturer. It was therefore not clear how many students understood the answer to each problem and how many merely copied out what was worked through for them. There were no formal workshop sessions and so there was limited opportunity for students to clarify or develop their understanding.

On marking exams and coursework it became clear the majority of the students had not achieved deep learning, as they were unable to apply knowledge far beyond the learned example. Questions phrased exactly as they had been during the lectures were answered reasonably well in coursework but those phrased slightly differently, for example, calculating a different value using the same equation, were observed to be attempted poorly. Similarly in the exam, simple questions that were similar to the lecture content were answered reasonably well but the students generally failed to answer more complex data analysis problems correctly, despite the method being presented during the lectures. It was perceived that this was due to a lack of understanding of the material as the students were able to adopt a surface approach to their learning. 
In order to achieve understanding of the material and apply this, students need to be able to make links between different topics. For example, in the kinetics topic, the rate constant, $k$, was discussed. When the dependence of rate of reaction upon temperature was covered, the same rate constant was discussed again as part of the Arrhenius relationship. Answers in the exam and questions from students prior to the exam indicated that they generally had not realised the value $k$ in Arrhenius was the same as they had covered already. Without this fundamental realisation, students were not able to link data together and perform the more complex calculations required of them at this level. This observation was also made for a number of other connections between and within topics.

\section{Through observation the}

\section{lecturer noted that the}

\section{students appeared capable} of answering more complex questions than the students in the previousyearhad. They also appeared to have more confidence to tackle

\section{unfa milia r questions when} they had the maps to refer to.

There are likely to be a number of factors contributing to these observed behaviours, some of which have already been discussed. One of the problems could be the way in which the information was presented. Slide presentations are linear, presenting information a piece at a time which can make appreciating more complex connections between current content and earlier content difficult. Reflecting on these problems led the lecturer to consider using concept mapping, in an attempt to encourage students to adopt deeper learning strategies.

\section{Concept mapping theory and methods}

Concept maps were developed ${ }^{5}$ in response to research into learning in children. The research was based on learning psychology by Ausubel ${ }^{6,7}$ and Ausubel et $\mathrm{al}^{8}$ which suggested that the process of learning required a knowledge framework already to be in place onto which new information can be fitted. The modern concept mapping system developed by Novak and Cañas ${ }^{9}$ includes concepts displayed in boxes linked by a line with a connecting word or phrase. These links are crucial in explaining the interconnections that exist between different areas of knowledge.
Ausubel differentiated between meaningful learning and rote learning practices that are commonly found in learning groups. Meaningful learning involves developing an understanding of the content and is a highly effective way of learning and retaining new information, it can be equated to 'deep learning' mentioned previously. Rote learning is a much more superficial process and involves students memorising concepts and processes without understanding them and is characterised by an inability to effectively develop meaning between ideas, even when related. This is witnessed by students able to repeat content 'learned' during an assessment but not able to use it to answer new questions posed. Bloom ${ }^{10}$, Hoffman $^{11}$ and Holden ${ }^{12}$ suggest that it is the task presented to the students that affects whether they undergo meaningful or rote learning. For example, testing their ability to do calculations would influence them to rote learn the relevant equations but testing their ability to explain the background theory and form new ideas may influence them to undergo a more meaningful learning process. Kinchin and Hay ${ }^{13}$, Mintzes et $\mathrm{al}^{14}$, Novak ${ }^{15}$ and Novak and Gowin $^{16}$ have all shown that the use of concept mapping in teaching and learning can encourage students to undergo meaningful learning.

The method used was to produce a series of concept maps using the Cmaptools program ${ }^{17}$. One map was created for the summing up of each major topic. This map consisted of concepts and associated equations from that topic with interconnections shown on the map. The aim was to provide the maps to students for use during a dedicated workshop session during which their ability to answer complex calculation questions would be tested. Each map was designed as a flow diagram with a central question as a starting point. Connectors radiated out from the start with sub-topic labels, one 'arm' for each sub-topic. An example of a concept map for the teaching of solution chemistry is shown in Figure 1. Each subtopic was then split into a number of sections.

For example, the pH subtopic was split into strong acids, weak acids and buffers. These were then split again into sections that explained the concept and any relevant equations. In appropriate places, instructions for the use of the equations were included, for example any assumptions that were required or a particular set of conditions. These were included to maintain the link between the theoretical content and the calculations, in an attempt to stop the learners from treating the equations as 'plug and play'.

During the workshop session, the room was arranged to enable the lecturer to walk around and easily reach all the students. While the students were tackling the set problems, the lecturer talked to each group of students, asking questions about what they were doing and why. This showed that the majority of students were happy with their work and were using the maps appropriately. Overall, $20 \%$ of the lecture sessions were replaced by workshop classes, which represents a significant increase when compared to the time given for similar activities previously. 


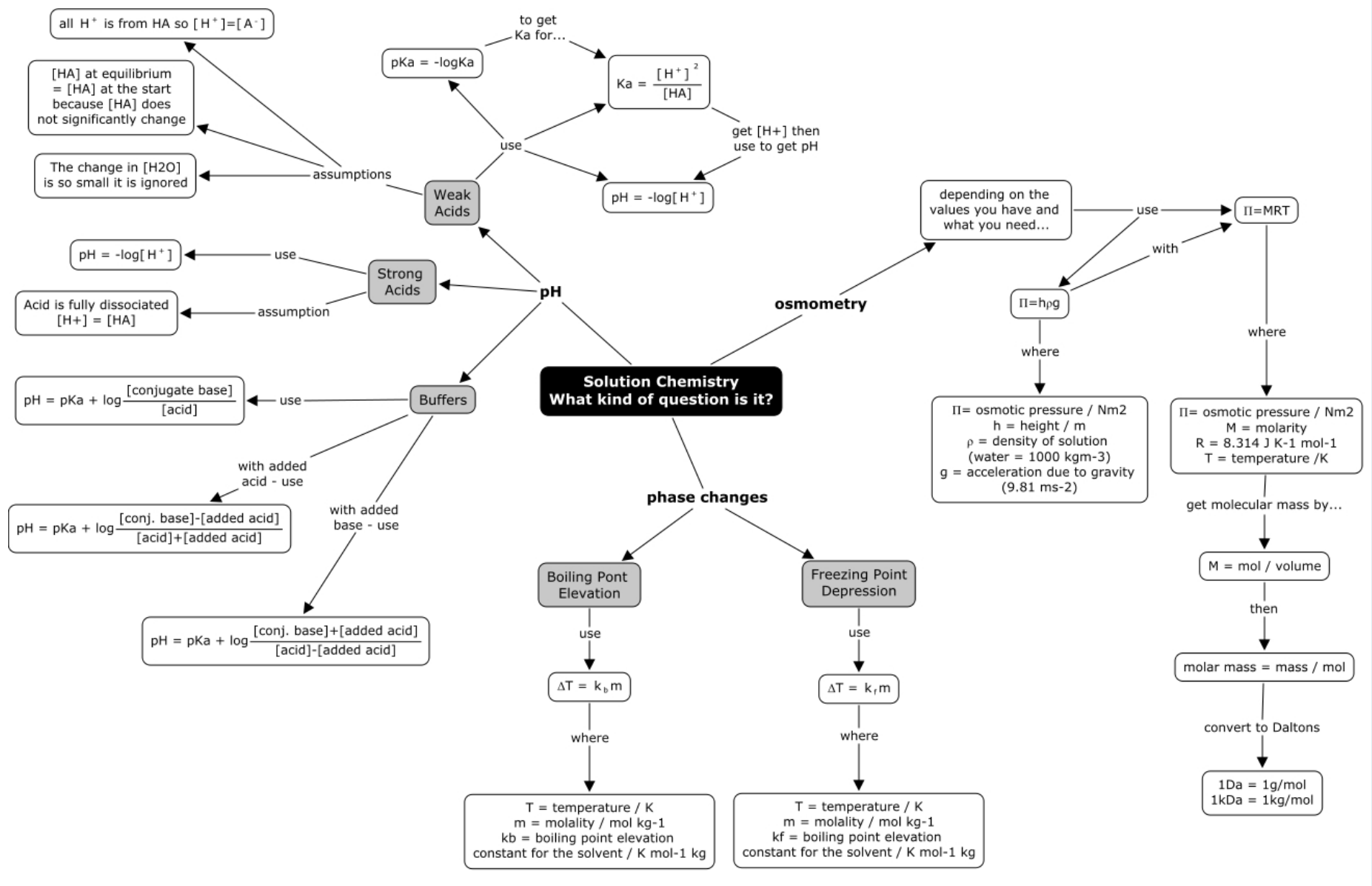

Figure 1: Example concept map used during the BMS1001 module showing content from the "solutions chemistry" section of the module.

Through observation the lecturer noted that the students appeared capable of answering more complex questions than the students in the previous year had. They also appeared to have more confidence to tackle unfamiliar questions when they had the maps to refer to. However, a small number of students appeared to struggle with the revised approach. On examination these tended to be those who had chosen not to use the map. In one case, a student claimed she found it extremely difficult to understand the map. She argued that she could not grasp the concept of a map or flow diagram at all and found the situation very frustrating. It transpired that this student learnt best from written information and rarely used or understood diagrams. It is suggested therefore that those students who are heavily reliant on non-visual learning habits may struggle more with the maps than those that are more capable of learning through imagery.
During each workshop, the map was introduced and students were shown how to follow the links to navigate the map. The idea being that if students could see the whole of a topic laid out with the connections shown clearly, they would then be able to make those connections for themselves during workshops and later during self-study. Students were then provided with examstyle questions and asked to complete them individually. The lecturer moved around the room and talked to students, asking and answering questions. The activity showed up areas of common confusion amongst students which were then discussed as a class. 
Using this approach enhanced dialogue between students and the lecturer, allowed areas of difficulty to be more clearly identified and enabled knowledge to be presented through an incremental process. This resulted in new knowledge being built from the known, making learning more effective. The last point was especially important as calculations were presented in greater detail and worked through rather than presented as a completed example, as had originally been the case. The answers were worked through together rather than presented on a PowerPoint slide. The students became more used to asking questions and greater dialogue resulted.

The students received workshops and maps that covered the sections of the module taught by the author which amounted to around a third of the content. The remainder of the content was provided by the same academics covering the same content during both instances of this module. The exam style and difficulty also remained unchanged during the project.

\section{Overall Module Outcomes}

The initial module was run in the academic year 2009-10 with 63 students taking the module and the modified module was run in 2010-11 for 49 students. During 2009-10 the average overall module mark was $44 \%$ and for the $2010-11$ year the average module mark was $59 \%$. It needs to be considered that during this time, the entry requirements of the biochemistry degree increased from 260 UCAS points to 300 points which may have had an impact on this mark improvement and there will be natural variation between cohorts.

However, less quantitatively, the students appeared more connected with the work during the workshops. They became more active in their learning, started to ask questions and help each other which had not happened noticeably before. Although the impact of this change was not investigated others have argued that it can be a powerful learning tool ${ }^{18}$. This was probably due to the atmosphere of the class which differed from that of a lecture class in which silence is expected. In addition, once students had formed an expectation of receiving a workshop and associated summary map, they appeared pleased to be given the resource and stated they liked the workshops and found them helpful. Student comments were obtained using module evaluation questionnaires on completion of the module. The questionnaires provide a voluntary comments section from which the following comments relating to workshop sessions and teaching resources were taken:

$\bullet$

- $\quad$ "For Dr $X$ and $D r Y$ it was useful to do practical questions"

- $\quad$ "Real effort made to engage by providing examples"

- "Handouts contained all the information required"

\section{Conclusions drawn from the project}

Concept mapping is a complex topic utilised in many arenas and has been increasingly documented in pedagogical research as well as in other areas. In this case, the concept maps were generated by a lecturer and presented complete to students. The act of creating the concept map is known to be one of the most important steps in their use and in future it will be important to consider if learning could be further enhanced by allowing students to engage in their creation.
However, what we have learned is that the maps provided the students with a visual cue indicating links between topics they may not have previously appreciated. It also provided the students with a compact summary of all the equations they would need to know and how to use them which may have reduced the amount of background reading they felt they had to do. This could have lead to the same surface learning as was experienced previously albeit in a seemingly more effective way.

It appeared that the combination of a map and the more relaxed workshop atmosphere made the module content more accessible for many of the students. It is worth noting however those students that did not find it useful, found it so unhelpful they seemed more confused than they would have been if the map had not existed at all. It is therefore important to consider the different types of learners in a class and provide different resources for as many of them as possible.

The project has informed the teaching of this module in a number of ways - to make time for workshops, to not assume prior knowledge and to make apparently obvious connections between topics clearer. Student comments relating to teaching methods were unanimously positive which indicates that taking this project further would potentially be well received by the students. While the resources produced and methods used showed promise in the context of this module they are by no means finished. Further refinement of the processes investigated here is required to maximise the benefits to the students and make the approach more applicable to other subjects and student groups.

In the future, if concept maps are to be included in the teaching of physical chemistry to first year non-specialist students, it would be useful to require the students to construct their own maps. This can support students create and construct meaning by establishing and explaining known connections and forming new ones. Finding time to allow this activity can be difficult and feedback may be negative as it can be perceived as harder by the students. However, as Chickering and Gamerson ${ }^{19}$ argue, communicating high expectations and promoting student time on a task are key elements to promote in undergraduate education. The overall impact of this approach indicates that student learning has improved and that most of those involved recognised the process as useful. This has encouraged staff to make further alterations to teaching methods for other modules and undertake further investigation into the utilisation of concept maps at Surrey. 


\section{References}

1. Nicoll, G; Francisco, J. S. (2001) An Investigation of the Factors Influencing Student Performance in Physical Chemistry. J Chem Educ. 78, 99-102.

2. Trigwell, K., Prosser, M. and Taylor, P. (1994) Qualitative differences in approaches to teaching first year university science Higher Education, 27 (1), 75-84.

3. Gibbs, G. (2010) Dimensions of Quality York, The Higher Education Academy

4. Marton, F. \& Saljo, R. (1976) On qualitative differences in learning. I - Outcome and Process British Journal of Educational Psychology 46, 4-11.

5. Novak, J. D., \& Musonda, D. (1991). A twelve-year longitudinal study of science concept learning. American Educational Research Journal, 28 (1), 117-153.

6. Ausubel, D. P. (1963). The psychology of meaningful verbal learning. New York: Grune and Stratton

7. Ausubel, D. P. (1968). Educational psychology: A cognitive view. New York: Holt, Rinehart and Winston.

8. Ausubel, D. P., Novak, J. D., \& Hanesian, H. (1978). Educational psychology: A cognitive view (2nd ed.). New York: Holt, Rinehart and Winston.

9. Novak J. D., Cañas A. J. (2008) The Theory Underlying Concept Maps and How to Construct and Use Them, Technical Report IHMC CmapTools, Florida Institute for Human and Machine Cognition (IHMC)

10. Bloom, B. S. (1956). Taxonomy of educational objectives; the classification of educational goals (1st ed.). New York: Longmans Green.

11. Hoffman, B. (1962). The tyranny of testing. New York: Corwell-Collier.

12. Holden, C. (1992). Study flunks science and math tests. Science Education, 26, 541

13. Kinchin, I. \& Hay, D. (2000) How a qualitative approach to concept map analysis can be used to aid learning by illustrating patterns of conceptual development Educational Research, Vol 42, Iss. 1, pp. 43-57.

14. Mintzes, J. J., Wandersee, J. H., \& Novak, J. D. (2000). Assessing science understanding: A human constructivist view. San Diego: Academic Press

15. Novak, J. D. (1990). Concept maps and vee diagrams: Two metacognitive tools for science and mathematics education. Instructional Science, Vol. 19, pp. 29-52.

16. Novak, J. D., \& Gowin, D. B. (1984). Learning how to learn. New York, NY: Cambridge University Press

17. A. J. Cañas, G. Hill, R. Carff, N. Suri, J. Lott, T. Eskridge, G. Gómez, M. Arroyo, R. Carvajal (2004). In: Concept Maps: Theory, Methodology, Technology, Proceedings of the First International Conference on Concept Mapping, A.J. Cañas, J.D. Novak, and F.M. González, Editors, Universidad Pública de Navarra: Pamplona, Spain. p. 125-133.

18. Mazur, E. (1996) Peer Instruction: A user's manual New York: Prentice Hall

19. Chickering, A.W. \& Gamerson, Z.F. (1987) Seven Principles for Good Practice in Undergraduate Education Racine, The Johnson Foundation/Wingspread

....if concept mapsare to be included in the teaching of physical c hemistry to first yea r non-spec ia list students, it would be useful to require the students to construct their own maps. This can support students create and construct meaning by establishing and explaining known connections and forming new ones. 